\title{
Trends of Abortion Care Utilization in a Medical College of Western Region of Nepal
}

\author{
Shrestha $\mathbf{R}^{\mathbf{1}^{*}}$, Adhikari $\mathbf{P}^{2}$ \\ ${ }^{1}$ Lecturer, ${ }^{2}$ Intern, Department of Obstetrics and Gynecology, \\ Gandaki Medical College \& Teaching Hospital, Pokhara, Nepal
}

\author{
Keywords \\ Maternal health, \\ Manual vacuum aspiration (MVA), \\ Safe abortion. \\ Corresponding author \\ ${ }^{*}$ Dr. Reecha Shrestha \\ Lecturer, Department of Obstetrics and \\ Gynecology \\ Gandaki Medical College \& Teaching \\ Hospital, Pokhara, Nepal \\ E-mail: drreechashrestha@gmail.com
}

\begin{abstract}
Introduction: Unsafe abortion is one of the important issues in reproductive and women's health in developing countries. Social values and stigmas have much role and have been obstacle in countries like Nepal for the utilization of safe abortion services.
\end{abstract}

Objectives: This study helps to provide brief overview of the pattern of abortion and its associated factors in a centre providing safe abortion services.

Methods: This is a retrospective study carried out in Gandaki Medical College Teaching Hospital after reviewing the records of all the women who underwent Manual Vacuum Aspiration (MVA). Age, gravida, week of gestation and type of abortion were noted and analysed.

Results: Maximum number of women belonged to age group of 25 - 29 and is primigravida. Most of them presented at fifth to ninth weeks of gestation and had incomplete abortion.

Conclusions: Awareness and education regarding the availability of safe abortion services and its practice would improve the women's reproductive health and well being.

\section{INTRODUCTION}

Among the abortions occurring worldwide, nearly half of them are unsafe and almost all of them (98\%) occur in developing countries ${ }^{1}$. Nepal being one of it has significant number of unsafe abortion cases due to poor access to the abortion care services, social values and stigmas ${ }^{2}$. Despite the liberalization of the abortion laws, the communal attitudes have limited the opportunity for women to utilize their right for safe abortion and thus sometimes lands in complication from unsafe abortion ${ }^{3}$. Expanding the care providers, innovative approaches for providing proper information and awareness are of much use for improving the current scenario of unsafe abortion ${ }^{4}$.

This study was conducted to find out the trends of abortion care utilization among the women who took safe abortion services from one of the medical colleges in Western Region of Nepal.

\section{METHODS}

This is a retrospective study carried out in the Gandaki Medical College Teaching Hospital. The hospital records of the patients from the obstetric ward who underwent Manual Vacuum Aspiration (MVA) from January 2017 to June 2017 were taken from record section. Age, gravida, week of gestation and type of abortion were noted. The data was entered in Microsoft Excel and analyzed.

Ethical clearance for the study was taken from Institutional Review Board of Gandaki Medical College and Teaching Hospital.

\section{RESULTS}

The total patients who underwent the safe abortion 
service during the study period were 256 . The mean age of the women taking the abortion service was 27.80 with maximum belonging to the age group 25-29 (Table 1).

Table 1: Age wise distribution of the patients

\begin{tabular}{ccc}
\hline Age & $\mathbf{N = 2 5 6}$ & \% \\
\hline $15-19$ & 32 & $12.50 \%$ \\
$20-24$ & 57 & $22.30 \%$ \\
$25-29$ & 63 & $24.60 \%$ \\
$30-34$ & 59 & $23.00 \%$ \\
$35-39$ & 32 & $12.50 \%$ \\
$40-45$ & 13 & $5.10 \%$ \\
Total & 256 & $100.00 \%$ \\
\hline
\end{tabular}

Similarly, most of the women who underwent Manual Vacuum Aspiration (MVA) are primigravida (Fig 1). Among the multigravida ( $\mathrm{N}=109)$, it was the first abortion for 77 of them, second for 23 of them, five had undergone for third time and its fourth time for four of them.

Fig 1: Gravida of the women underwent MVA

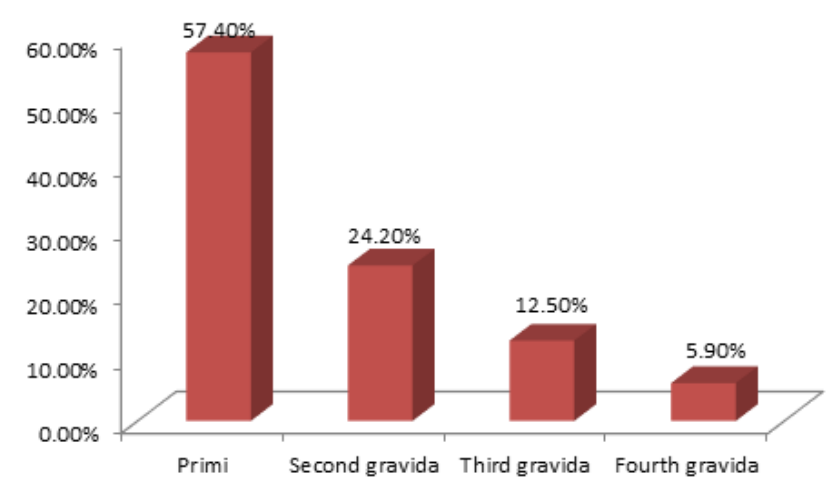

The maximum number of women presented at fifth to ninth weeks of gestation followed by 10 to 14 weeks of gestation (Table 2). The mean week of presentation is 10.19 weeks.

Table 2: Weeks of gestation of the women underwent MVA

\begin{tabular}{ccc}
\hline Weeks of gestation & $\mathbf{N = 2 5 6}$ & \% \\
\hline $5-9$ & 121 & $47.30 \%$ \\
$10-14$ & 107 & $41.80 \%$ \\
$15-19$ & 21 & $8.20 \%$ \\
$20-24$ & 7 & $2.70 \%$ \\
Total & 256 & $100.00 \%$ \\
\hline
\end{tabular}

Similarly, most of them who underwent MVA were diagnosed of incomplete abortion (Table 3).
Table 3: Type of abortion

\begin{tabular}{lcc}
\hline Type of abortion & N=256 & Percentage \\
\hline Incomplete & 189 & $73.80 \%$ \\
Missed & 34 & $13.30 \%$ \\
Threatened & 22 & $8.60 \%$ \\
Septic & 11 & $4.30 \%$ \\
Total & 256 & $100.00 \%$ \\
\hline
\end{tabular}

\section{DISCUSSION}

WHO defines abortion as the expulsion or extraction of fetus from its mother weighing 500 gram or less when it is not capable of independent survival before 20 weeks of gestation $^{5}$. Though abortion rate has been declined in the developed countries it is still significant in developing and low income countries ${ }^{6}$.

Our study showed the majority of women who underwent MVA were belonging to the age group 25 to 29 years which was in consistent with the study conducted by Paudel et $a l^{7}$ in a Maternity Hospital in Kathmandu. These age groups of women are recently married age group in our socioeconomic scenario. It may be either due to the lack of family planning methods have undergone conception and landed in complication after medically terminating pregnancy or as a result of spontaneous complication in first trimester.

Similarly, our study demonstrated that most of those who underwent MVA were nulliparous in contrast to the other Asian countries which showed the multiparous accounted for high number of reported abortions ${ }^{8}$. Though exact cause is not known, this may be due to intake of medial termination pills earlier and unavailability of family planning measures.

Those women who underwent MVA presented to fifth to ninth week of gestation in our centre though mean week of presentation was 10.19. Nepal's 2002 abortion law has stated that pregnancy termination up to only 12 weeks is available for any indication by request ${ }^{9}$. Though our study suggested there were significant number of MVA done above 14 weeks too. It may be due to the case of missed abortion diagnosed later or patient presented with incomplete abortion after self intake of medical termination pills after 12 weeks. Among the different types of abortion the majority of them were diagnosed as incomplete abortion.

There has been increased utilization of safe abortion 
care after its legalization in $\mathrm{Nepal}^{7,10}$. Though still there have been some socio-cultural barriers, issues regarding sex selective abortion, and post abortion contraceptive measures; which are the rooms for further improvement.

As our study was retrospective and single centered, our limitations were that we couldn't include other significant variables like socioeconomic background, literacy level of the women. Similarly, we also couldn't differentiate those incomplete abortion we encountered were spontaneous or as a result of medical termination pills intake. Further studies are recommended for discovering the medical termination pill using habits by buying from the pharmacy without proper medical consultation.

\section{CONCLUSIONS}

Our study concluded that among those seeking abortion services and underwent MVA in our institution majority were primi women of age group $25-29$ years at fifth to ninth weeks of gestation with incomplete abortion. Awareness among the women regarding the availability of safe abortion facilities will further improve the women's reproductive health and well being.

\section{REFERENCES}

1. [Internet]. Who.int. 2018 [cited 4 April 2018]. Available from: http://www.who.int/ reproductivehealth/publications/unsafe_abortion/ induced_abortion_2012.pdf?ua=1

2. Bhandari T, Dangal G. Abortion Practices in Nepal: What does Evidence Show? Nepal Journal of Obstetrics and Gynaecology. 2015; 10(1): 3.
3. Hald S, Sondergaard D. A gap between Law and Practice: A Community's Perception of Unmarried Women's Abortion Options in Nepal. Health Prospect. 2014; 12(2).

4. Ganatra B, Johnson B. Evidence-based practices can improve safety and timeliness of care for women needing safe termination of pregnancy. BJOG: An International Journal of Obstetrics \& Gynaecology. 2016; 123(10): 1692-1692.

5. Cunningham FG, Leveno KJ, Bloom SL, Hauth J, Rouse D, Spong C. Williams' Obstetrics. 23rd ed. New York: The McGraw-Hill Companies, Inc; 2010.

6. Sedgh G, Bearak J, Singh S, Bankole A, Popinchalk A, Ganatra B et al. Abortion incidence between 1990 and 2014: Global, regional, and subregional levels and trends. The Lancet. 2016; 388(10041): 258-267.

7. Paudel P, Paudel L, Bhochhibhoya M, Vaidhya SA, Shah $\mathrm{N}$, Khatiwada D. Pattern of abortion care in a tertiary level maternity hospital in Nepal. J Nepal Med Assoc. 2013 Jul-Sep; 52(191): 432-6.

8. Chae S, Desai S, Crowell M, Sedgh G, Singh S. Characteristics of women obtaining induced abortions in selected low- and middle-income countries. PLOS ONE. 2017; 12(3): e0172976.

9. Samandari G, Wolf M, Basnett I, Hyman A, Andersen K. Implementation of legal abortion in Nepal: A model for rapid scale-up of high-quality care. Reproductive Health. 2012; 9(1).

10. Wu W-J, Maru S, Regmi K, Basnett I. Abortion Care in Nepal, 15 Years after Legalization: Gaps in Access, Equity, and Quality. Health and Human Rights. 2017; 19(1): 221-230. 